\title{
Synthesis and characterization of Sn-doped CdZnS nanoparticles
}

\author{
R SHRIVASTAVA ${ }^{1, *}$ and S C SHRIVASTAVA ${ }^{2}$ \\ ${ }^{1}$ Department of Physics, Shri Shankaracharya Engineering College, Bhilai, Chhattisgarh 490 020, India \\ ${ }^{2}$ Department of Mathematics, Rungta College of Engineering and Technology, Bhilai, Chhattisgarh 490 024, India
}

MS received 26 December 2014; accepted 16 April 2015

\begin{abstract}
Tin (Sn)-doped cadmium zinc sulphide nanoparticles $(\mathrm{CdZnS}: \mathrm{Sn})$ were synthesized by the chemical bath deposition method with two different concentrations of Sn ( 2 and 4 mol\%). X-ray diffraction (XRD) pattern reveals the formation of $\mathrm{CdZnS}$ nanoparticles with cubic and hexagonal structure. It was observed that the presence of Sn does not alter the structure of $\mathrm{CdZnS}$. Average crystallite size was measured from XRD data by using Scherrer's formula. From the study of absorption spectra, band-to-band absorption was obtained at 460 and $490 \mathrm{~nm}$, respectively, for the Sn-doped ( 2 and $4 \mathrm{~mol} \%$ ) CdZnS nanoparticles. Energy bandgap for undoped and Sn-doped CdZnS varies from 3.5 to $2.9 \mathrm{eV}$ with error $\pm 0.05 \mathrm{eV}$. The presence of Sn was confirmed by energy-dispersive $\mathrm{X}$-ray analysis. The effect of dopant concentration on the photoluminescence (PL) intensity has also been studied. The PL emission peak has been observed at 540, 550 and $560 \mathrm{~nm}$ for the Sn-doped (CdZnS, CdZnS $2 \mathrm{~mol} \%$ and CdZnS 4 mol\%), respectively, nanoparticles. XRD and PL analyses demonstrate that the $\mathrm{Sn}^{2+}$ ions uniformly substitute $\mathrm{Cd}^{2+}$ sites or interstitial sites in $\mathrm{CdZnS}$ lattice, which influence the optical properties. Increase in the concentration of Sn shifts the UV-vis absorption spectra and PL emission spectra towards higher wavelength side. Particle size and the crystallinity of CdZnS : Sn nanoparticles were confirmed through atomic force microscopy.
\end{abstract}

Keywords. CdZnS; chemical bath deposition; thin films; structural properties.

\section{Introduction}

Cadmium zinc sulphide $(\mathrm{CdZnS})$ alloy compounds have attracted technological interest, because the energy gap can be tuned and the lattice parameters can be varied. ${ }^{1}$

$\mathrm{CdZnS}$ films have been deposited in a variety of ways: vacuum evaporation, metalorganic chemical vapour deposition, chemical bath deposition (CBD), spray pyrolysis, successive ionic layer absorption and reaction (SILAR) and the dip technique. Among these techniques, CBD is most attractive because of its advantageous features over other deposition techniques and because it is a cheap and easily applicable technique. This method gives high-quality films at low temperatures, requires slow evaporation temperatures and easily coats very large surfaces. The only requirement for using this method is the knowledge of chemistry of the process. ${ }^{2}$

$\mathrm{CdZnS}$ thin films have been widely used as a wide bandgap window material in heterojunction solar cell ${ }^{3-7}$ and in photoconductive devices. ${ }^{8}$ In solar cell systems, where CdS films have been demonstrated to be useful, the replacement of $\mathrm{CdS}$ with the higher bandgap ternary $\mathrm{CdZnS}$ has led to a decrease in window absorption losses and has resulted in the increase of short-circuit current in

*Author for correspondence (ritu_10101010@rediffmail.com) the solar cell. ${ }^{9}$ This $\mathrm{CdZnS}$ ternary compound is also potentially useful as a window material for the fabrication of $\mathrm{p}-\mathrm{n}$ junctions without lattice mismatches of the devices based on quaternary materials like $\mathrm{CuIn}_{x} \mathrm{Ga}_{1-x} \mathrm{Se}_{2}{ }^{10}$ or $\mathrm{CuIn}\left(\mathrm{S}_{z} \mathrm{Se}_{1-z}\right)_{2}$. ${ }^{11}$ However, the resistivity of $\mathrm{CdZnS}$ films increases rapidly with the composition of zinc. It is evident that the composition dependence of resistivity is a basic property of the $\mathrm{CdZnS}$ solid-solution system and is not appreciably altered by the method of preparation. This high resistivity of $\mathrm{CdZnS}$ films limited their utilization as a doping material in most heterojunction devices. The resistivity can be reduced appreciably by an incorporation of donors and by doping the films with Sn. Earlier, Sn-doped CdS films, produced by using tartaric acid as complexing agent, were less transparent. ${ }^{12}$ As the transmittance of light is the most important requirement of the window layer in a thin film structured solar cells, the search for methods to form very high transparent $\mathrm{CdZnS}$ films by doping $\mathrm{Sn}$ is highly warranted. In this paper, we present the fabrication of more transparent Sn-doped CdZnS films at a low dopant concentration by using the CBD technique. Additionally, the optical, structural and morphological properties of the films are also presented. The resulting $\mathrm{CdZnS}: \mathrm{Sn}$ thin films were found to retain the beneficial optical properties for application as a window material in solar cells. 


\section{Experimental}

In this study, nanocrystalline films were prepared on glass substrates by the CBD technique. The microscopic glass slides of dimensions $24 \times 75 \mathrm{~mm}$ were used as substrates. The slides were first cleaned with $\mathrm{H}_{2} \mathrm{SO}_{4}$, acetone, double distilled water and ultrasonic cleaner. Then the dried glass slides were dipped vertically into a mixture of solution of $1 \mathrm{M}$ cadmium acetate, $1 \mathrm{M}$ zinc acetate, triethanolamine, $30 \%$ aqueous ammonia and thiourea. Briefly, $0.01 \mathrm{M} \mathrm{CdCl}_{2}$ was used as flux and $0.01 \mathrm{M}$ solution of $\mathrm{SnCl}_{2}$ was used in varying concentrations. All solutions were prepared in double distilled water. The mixture was kept in a water bath for $1 \mathrm{~h}$ at $60^{\circ} \mathrm{C}$ temperature. The films were then formed on a glass substrate by doping the substrate in the mixture vertically. The prepared samples were then washed with double distilled water and dried at room temperature. The $\mathrm{pH}$ value of this mixture was found to vary from 11.2 at beginning to $10.9 \mathrm{pH}$ at the end of the deposition.

\section{Measuring instruments}

$\mathrm{X}$-ray diffraction $(\mathrm{XRD})$ measurements in the incidence mode with $0.5^{\circ}$ of beam inclination were performed, using a monochromatic $\mathrm{CuK} \alpha$ radiation $(\lambda=1.540600 \AA)$ and an aperture diaphragm of $0.2^{\circ}$, in a Rigaku RU : H2R Xray diffractometer. Data were collected sequentially at a $2 \theta$ angle between $10^{\circ}$ and $60^{\circ}$. An energy-dispersive X-ray analysis (EDAX) study was made by using a JEOL JSM 5600 scanning electron microscope (SEM). Transmission electron microscopy (TEM) measurements were made using a higher resolution electron microscope, Philips CM 120, operating at an accelerating voltage of $100 \mathrm{kV}$ and capabilities of a point-to-point resolution of $2 \AA$. The photoluminescence (PL) excitation source was a highpressure $\mathrm{Hg}$ source from which $365 \mathrm{~nm}$ radiation was selected by using Carl Zeiss interference filter. An RCA6217 photomultiplier tube operated by a highly regulated power supply was used for the detection of PL light emission. The integrated light output in the form of current was recorded by a sensitive Polyflex galvanometer $\left(10^{-9} \mathrm{~A} \mathrm{~mm}^{-1}\right)$. A prism monochromator was used for PL emission spectral studies. Optical absorption data were obtained with a Cary Bio 50 Varian UV-vis spectrophotometer.

\section{Results and discussion}

\subsection{XRD study}

XRD pattern of undoped $\mathrm{CdZnS}$ and Sn-doped CdZnS films are presented in figure 1 . These patterns correspond to (100), (110), (111), (002), (211) and (220). These diffractographs show that the intensities of diffraction peaks

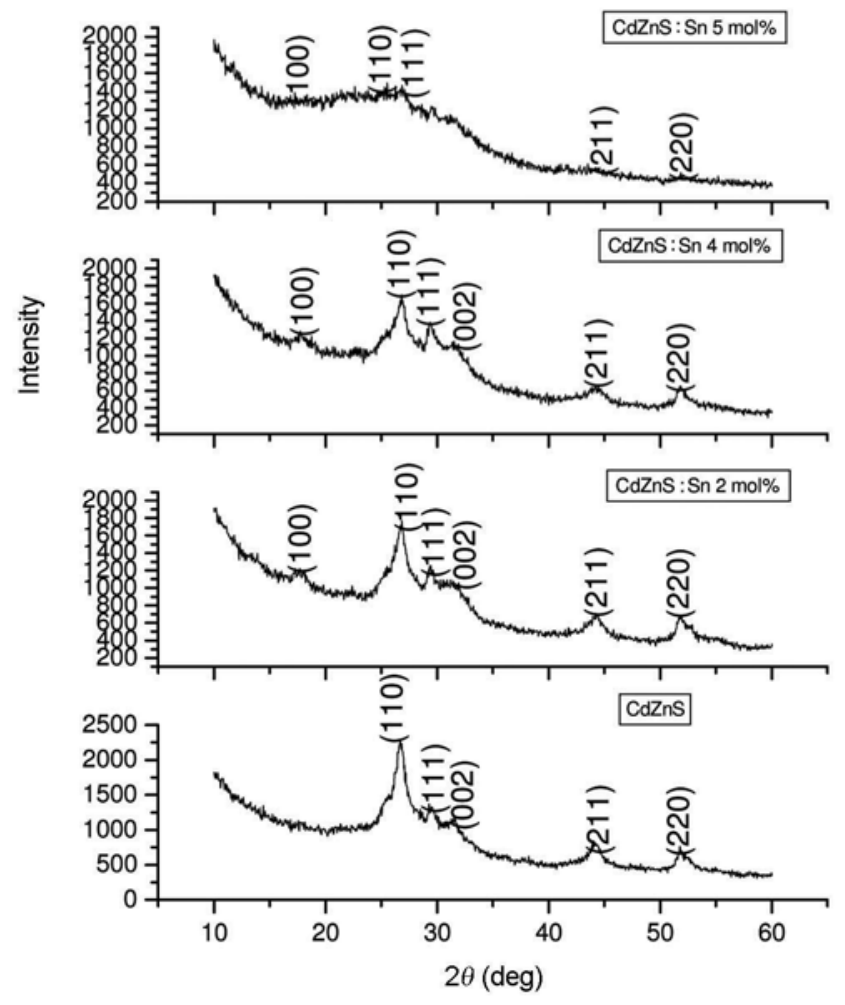

Figure 1. XRD spectra of CdZnS films with different doping concentrations of $\mathrm{Sn}$ and for undoped $\mathrm{CdZnS}$.

declined as Sn concentrations increased, i.e., Sn doping within $\mathrm{CdZnS}$ films caused the crystallinity to degenerate. Moreover, the XRD pattern of $\mathrm{CdZnS}$ : Sn films that were prepared without the formation of secondary phase show high (002) peak intensities; which indicates that such film exhibits $c$-axis preferred orientation. In addition, increased Sn concentrations slightly shift the (110) peaks to higher diffraction angles. Sharma $e t \mathrm{ll}^{13}$ have reported that the (110) peak shift to a high angle is because dopant ions have smaller radii than $\mathrm{Cd}^{2+}$ ions and dopant ions only substituted for $\mathrm{Zn}^{2+}$ ions. The average crystallite size $(d)$ of these samples was estimated using Scherrer's formula ${ }^{14}$

$$
\mathrm{L}=\frac{0.94 \lambda}{\beta \cos \theta},
$$

where $\beta$ is the full-width at half-maxima (FWHM) in radians, $\lambda$ the X-ray wavelength of $1.5406 \AA$ and $\theta$ the Bragg diffraction angle. The calculated average crystallite sizes of undoped CdZnS films were $15 \mathrm{~nm}$. When the Sn concentration increases the average crystallite size decreases to about $1-2 \mathrm{~nm}$.

\subsection{SEM study}

SEM micrographs of the film surfaces of CdZnS and $\mathrm{CdZnS}$ with 2 and $4 \mathrm{~mol} \%$ Sn-doped films are shown in 
Table 1. XRD results for $\mathrm{CdZnS}, \mathrm{CdZnS}: \mathrm{Sn}$ thin films for varying concentrations of $\mathrm{Sn}$.

\begin{tabular}{|c|c|c|c|c|c|c|c|}
\hline Sample & FWHM & $2 \theta(\mathrm{deg})$ & $d(\mathrm{~nm})$ & $(h k l)$ & Crystallite size & Lattice strain & $I / I_{0}(\%)$ \\
\hline $\mathrm{CdZnS}$ & $\begin{array}{l}1.198 \\
0.6496 \\
0.4995 \\
0.3996 \\
0.7999\end{array}$ & $\begin{array}{l}26.6849 \\
29.5823 \\
31.4806 \\
44.0692 \\
51.7622\end{array}$ & $\begin{array}{l}3.3375 \\
3.017 \\
2.389 \\
2.053 \\
1.264\end{array}$ & $\begin{array}{l}110 \\
111 \\
002 \\
211 \\
220\end{array}$ & $\begin{array}{r}7.12 \\
13.21 \\
17.27 \\
22.41 \\
11.53\end{array}$ & $\begin{array}{l}0.0220 \\
0.0107 \\
0.0077 \\
0.0043 \\
0.0072\end{array}$ & $\begin{array}{c}100 \\
57 \\
51 \\
35.8 \\
33.27\end{array}$ \\
\hline $\mathrm{CdZnS}: \mathrm{Sn} 2 \mathrm{~mol} \%$ & $\begin{array}{l}0.4995 \\
1.148 \\
0.5495 \\
0.4499 \\
0.348 \\
0.7492\end{array}$ & $\begin{array}{l}17.693 \\
26.8348 \\
29.3325 \\
31.2308 \\
44.219 \\
51.7622\end{array}$ & $\begin{array}{l}5.0088 \\
3.31 \\
3.04 \\
2.86 \\
2.04 \\
1.76\end{array}$ & $\begin{array}{l}100 \\
110 \\
111 \\
002 \\
211 \\
220\end{array}$ & $\begin{array}{r}16.82 \\
7.43 \\
15.62 \\
19.16 \\
25.75 \\
12.30\end{array}$ & $\begin{array}{l}0.0140 \\
0.0210 \\
0.0092 \\
0.0070 \\
0.0037 \\
0.0067\end{array}$ & $\begin{array}{c}69 \\
100 \\
71 \\
\\
40.2 \\
37.27\end{array}$ \\
\hline CdZnS : Sn 4 mol\% & $\begin{array}{l}0.6994 \\
1.124 \\
0.4994 \\
0.399 \\
0.2996 \\
0.7493\end{array}$ & $\begin{array}{l}17.743 \\
26.9347 \\
29.3325 \\
30.1318 \\
44.1691 \\
51.8621\end{array}$ & $\begin{array}{l}4.99 \\
3.31 \\
3.04 \\
2.96 \\
2.04 \\
1.76\end{array}$ & $\begin{array}{l}100 \\
110 \\
111 \\
002 \\
211 \\
220\end{array}$ & $\begin{array}{c}12.01 \\
7.59 \\
17.18 \\
21.55 \\
29.9 \\
12.32\end{array}$ & $\begin{array}{l}0.0196 \\
0.0228 \\
0.0083 \\
0.0065 \\
0.0032 \\
0.0067\end{array}$ & $\begin{array}{c}75 \\
100 \\
81.8 \\
69.61 \\
37.87 \\
38.46\end{array}$ \\
\hline CdZnS : Sn 5 mol\% & $\begin{array}{l}0.1998 \\
0.996 \\
0.5197 \\
0.5495 \\
0.1998\end{array}$ & $\begin{array}{l}17.2434 \\
25.5359 \\
29.4824 \\
43.5197 \\
51.8621\end{array}$ & $\begin{array}{l}5.137 \\
3.512 \\
3.012 \\
2.093 \\
1.766\end{array}$ & $\begin{array}{l}100 \\
110 \\
111 \\
211 \\
220\end{array}$ & $\begin{array}{c}22.02 \\
8.55 \\
16.52 \\
16.259 \\
26.19\end{array}$ & $\begin{array}{l}0.0057 \\
0.0192 \\
0.0086 \\
0.0060 \\
0.0018\end{array}$ & $\begin{array}{c}93.11 \\
97.25 \\
100 \\
40.86 \\
34.44\end{array}$ \\
\hline
\end{tabular}
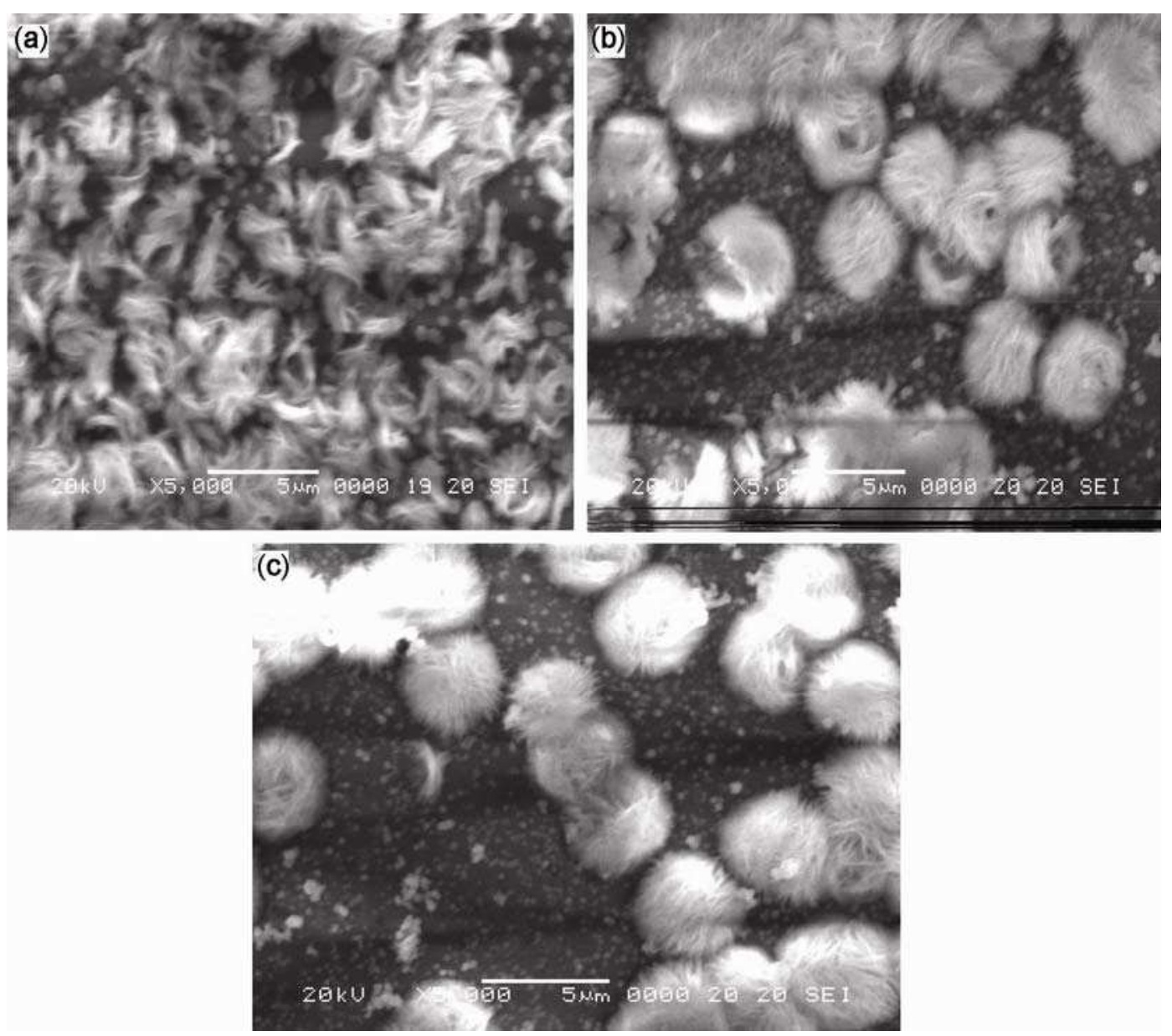

Figure 2. SEM micrograph of (a) undoped CdZnS, (b) 2 mol\% Sn-doped CdZnS and (c) 4 mol\% Sn-doped CdZnS films. 
figure $2 \mathrm{a}-\mathrm{c}$, respectively. These images reveal that the films are compact, free of colloidal particles and are in good order. The plane view of SEM micrographs of undoped CdZnS films shows the leafy-like structure. However, the doped samples do not display the appearance from the surface micrographs of 2, 4 and $5 \mathrm{~mol} \% \mathrm{SnCl}_{2}$ doped $\mathrm{CdZnS}$ films. According to the previous report ${ }^{15}$ the leafy-like or fiber-like structure was induced by the shortness of $\mathrm{OH}$ and $\mathrm{OR}$ groups. Thus, a relatively smooth surface will be obtained when component materials can provide enough $\mathrm{OH}$ and $\mathrm{OR}$ groups. The sizes of grains were in the same range as those that show homogeneous distribution of Sn dopant in films. Increasing the dopant led to grain growth. The surface grain size becomes larger with less void area, and led to the formation of highquality film surfaces. These SEM micrographs also reveal that Sn doping of $\mathrm{CdZnS}$ films can increase the average crystallite size. The grain size for undoped, 2 and $4 \mathrm{~mol} \%$ doped films are 4.748, 5.929 and $8.525 \mathrm{~nm}$, respectively (as determined by IMAGE J software). The result agrees with XRD measurements.

\subsection{AFM study}

AFM images of the $\mathrm{CdZnS}: \mathrm{Sn}$ thin films are shown in figure $3 a-c$. These images show that the surface morphologies of the films were strongly dependent on the dopant concentration. In addition, it is apparent that the reduction of surface roughness results from an increase in the average crystallite size in the $\mathrm{CdZnS}$ films after $\mathrm{Sn}$ substitution. The plot of surface levels of $\mathrm{CdZnS}: \mathrm{Sn}$ thin films as a function of Sn concentration is shown. A significant improvement of surface roughness with Sn doping can be noticed. The RMS value decreases with the increase in $\mathrm{Sn}$.

We calculated another two parameters, i.e., the skewness $\left(S_{\mathrm{sk}}\right)$ parameter and the kurtosis parameter $\left(S_{\mathrm{ku}}\right){ }^{16}$ Both the parameters have no units, they are pure numbers

$$
\begin{aligned}
& S_{\mathrm{sk}}=\frac{1}{M N S_{q}^{3}} \sum_{k=0}^{M-1} \sum_{l=0}^{N-1}\left[z\left(x_{k}, y_{l}\right)-\mu\right]^{3}, \\
& S_{\mathrm{ku}}=\frac{1}{M N S_{q}^{4}} \sum_{k=0}^{M-1} \sum_{l=0}^{N-1}\left[z\left(x_{k}, y_{l}\right)-\mu\right]^{4} .
\end{aligned}
$$

The $S_{\text {sk }}$ parameter has been used in order to describe the asymmetry of the height distribution histogram. It was seen that the $S_{\text {sk }}$ parameter exhibit a positive value close to zero. This indicates a symmetric height distribution. Another descriptive parameter is the kurtosis one: smaller values of the $S_{\mathrm{ku}}$ parameter indicate broader height
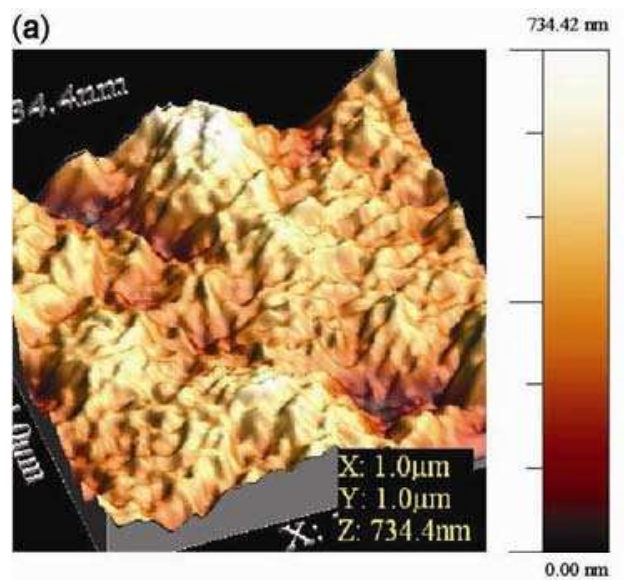

(b)
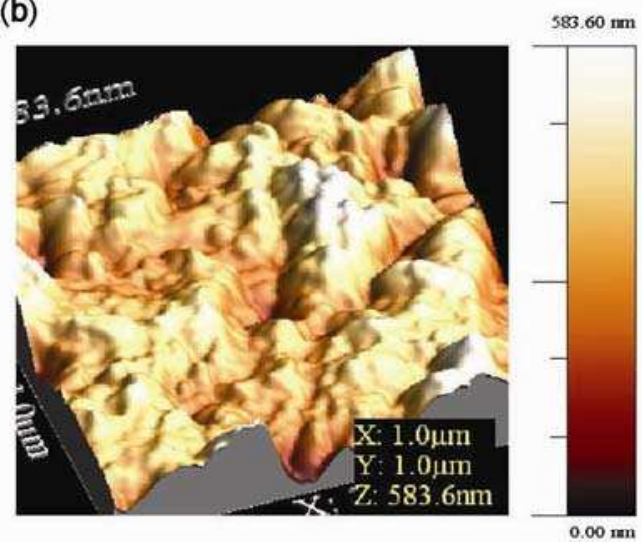

(c)
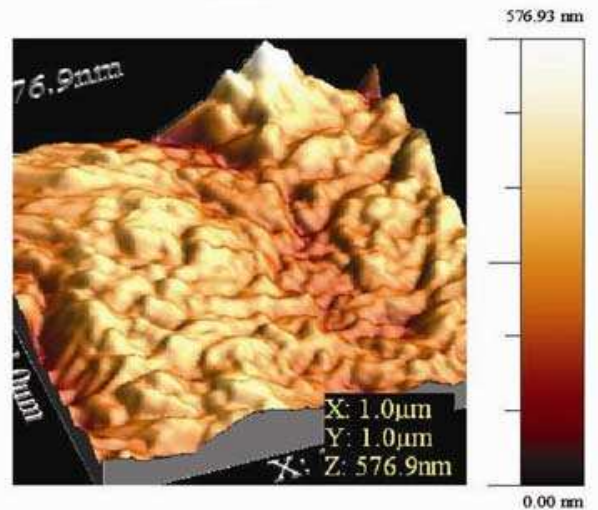

Figure 3. AFM micrograph of (a) CdZnS, (b) CdZnS : Sn 2 mol\% and (c) $\mathrm{CdZnS}: \mathrm{Sn} 4 \mathrm{~mol} \%$ thin films. 
Table 2. Roughness profiles of $\mathrm{CdZnS}$ and $\mathrm{CdZnS}: \mathrm{Sn}$ thin films with varying concentrations of Sn.

\begin{tabular}{lcccc}
\hline Film & RMS value & Roughness average & Skewness & Kurtosis \\
\hline CdZnS & 104 & 81.9213 & 0.0761 & 3.258 \\
CdZnS : Sn 2 mol\% & 79 & 62.97 & 0.0787 & 3.2414 \\
CdZnS : Sn 4 mol\% & 61 & 48 & 0.127 & 4.0318 \\
\hline
\end{tabular}

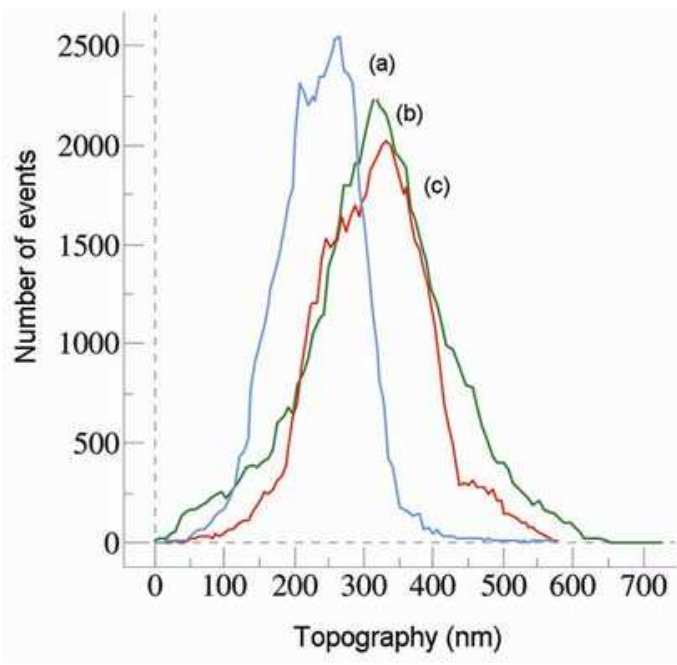

Figure 4. Roughness profiles of (a) $\mathrm{CdZnS}$, (b) $\mathrm{CdZnS}: \mathrm{Sn}$ $2 \mathrm{~mol} \%$ and (c) CdZnS : Sn 4 mol\% films for undoped and Sndoped film.

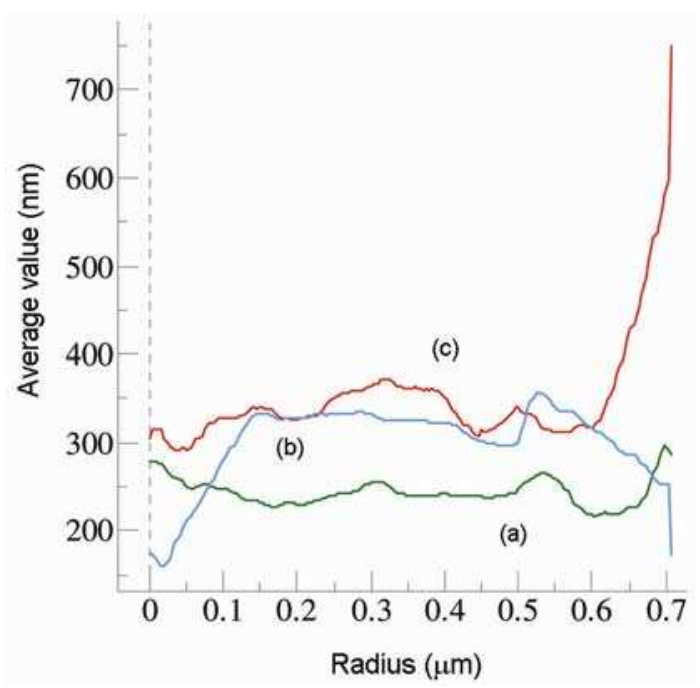

Figure 5. Average radial profile for (a) $\mathrm{CdZnS}$, (b) $\mathrm{CdZnS} \mathrm{:}$ Sn $2 \mathrm{~mol} \%$ and (c) CdZnS : Sn 4 mol\% films.

distribution, whereas values higher than 3.0 indicate sharper height distribution. ${ }^{16}$ At the microscale (hundreds of microns) the employed surface is relatively smooth and uniform. At the nanoscale, all the samples showed small irregularities, which can be seen in AFM images. The rough surfaces of the component attributed to the small grain size. This is also clear from table $2 .^{3}$ Also the typical average roughness profile for respective samples is shown in figure 4. This can determine the growth and coalescence of randomly oriented grains of different sizes. The average radial profile is shown in figure 5. It is clear that the average radial value increases with the increase in the doping concentration of Sn. It is also in a good agreement with XRD and SEM results.

\subsection{EDAX study}

EDAX spectrum, as shown in figures 6-8, of $\mathrm{CdZnS}$, $\mathrm{CdZnS}: \mathrm{Sn} 2 \mathrm{~mol} \%$ and CdZnS : Sn 4 mol\% nanoparticles, respectively, shows the presence of major chemical elements, namely cadmium, sulphur, zinc and Sn. An intense peak for Sn was found in the spectrum due to its higher concentration as in comparison to cadmium and zinc. The elemental composition analysis for Sn-doped $\mathrm{CdZnS}$ is shown in the table 3, which also confirms that majority of $\mathrm{Sn}^{2+}$ ions are doped with $\mathrm{CdZnS}$. The traces of $\mathrm{Si}$ and $\mathrm{O}$ are due to the glass substrate.

\subsection{PL studies}

Upon excitation at $350 \mathrm{~nm}$, the samples show luminescence in the blue region. As the $\mathrm{Sn}$ concentration increases the intensity of luminescence increases effectively. The intensity of $0.01 \mathrm{M} \mathrm{Sn-doped} \mathrm{samples} \mathrm{is} \mathrm{enhanced} \mathrm{to} \mathrm{that}$ of the undoped sample. The enhancement in the emission intensity on Sn doping is attributed to the increase of defect densities in the bandgap. The emission peak for Sn-doped CdZnS sample shifted to red region with increasing intensity in the spectrum as compared to the base material $\mathrm{CdZnS}$. Thus, it confirms that luminescence property of nanoparticles enhanced when Sn was introduced into the lattice. ${ }^{17}$ Similar explanation was given by Devi et $a l^{18}$ for the peak nanocrystalline CdS.

The PL spectra of the nanocrystalline CdZnS samples are shown in figure 9. A peak was obtained at 540, 550 and $560 \mathrm{~nm}$ for CdZnS, CdZnS : Sn $2 \mathrm{~mol} \%$ and $4 \mathrm{~mol} \%$ samples corresponding to bandgap $3.5 \pm 0.05,3.0 \pm 0.05$ and $2.9 \pm 0.05 \mathrm{eV}$, respectively. It can be noted that the PL peak is obtained at photon energies less than the effective peak observed by absorption peak, and the peak shifts towards higher wavelength with increasing particle size. When the particle size increases, the effective bandgap decreases, therefore the emitted photon has a comparatively higher wavelength peak, which may be 


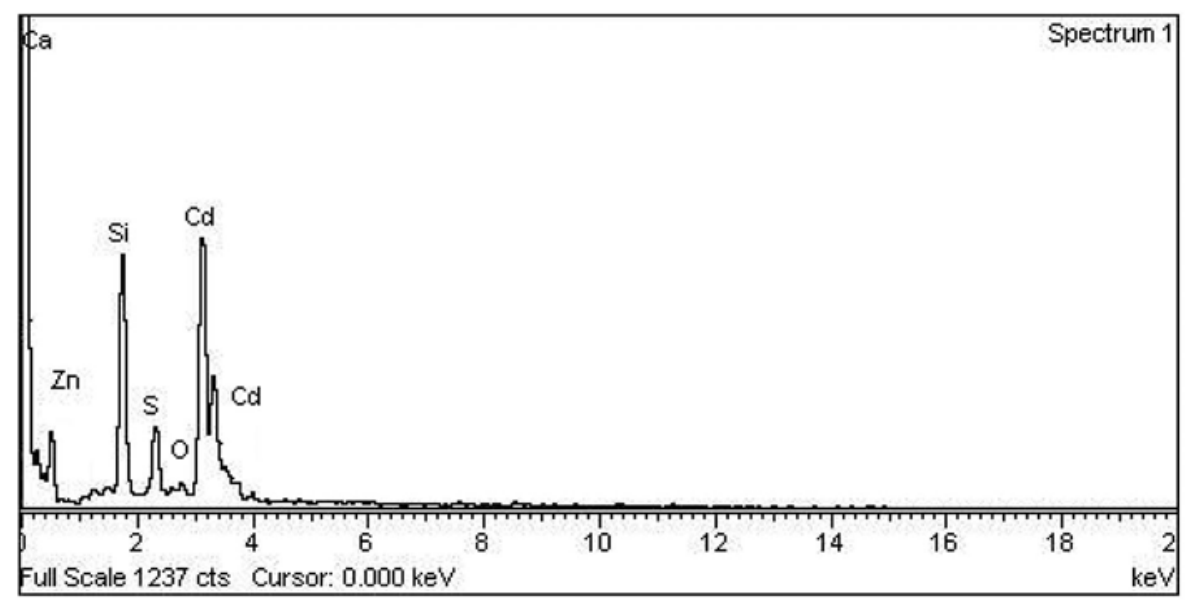

Figure 6. EDAX spectra of undoped CdZnS films.

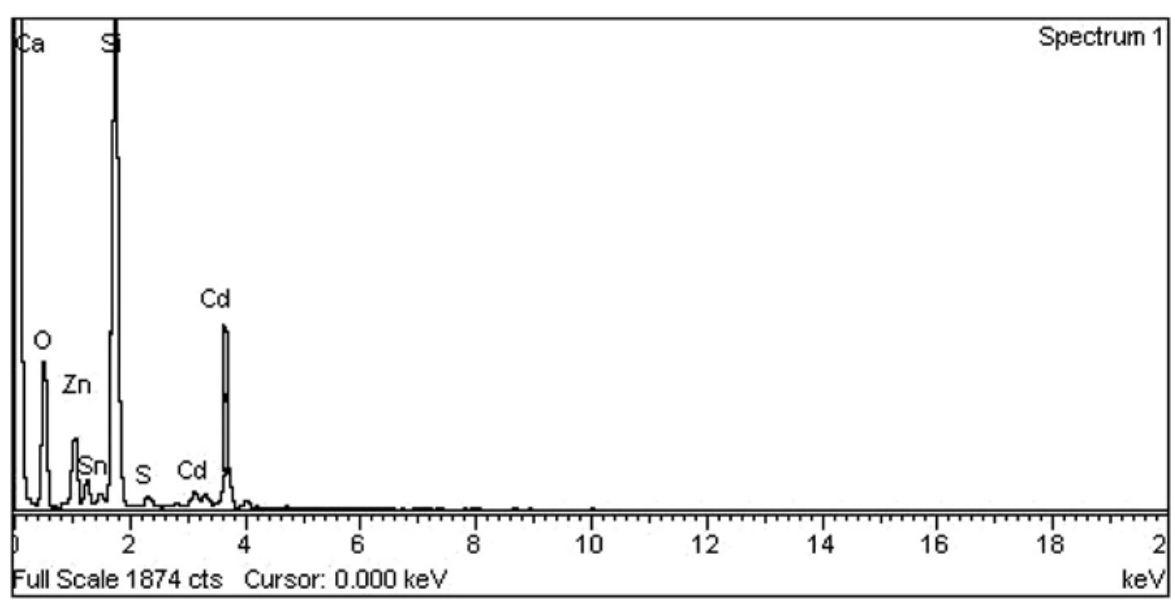

Figure 7. EDAX spectra for CdZnS : Sn film with $2 \mathrm{~mol} \% \mathrm{Sn}$.

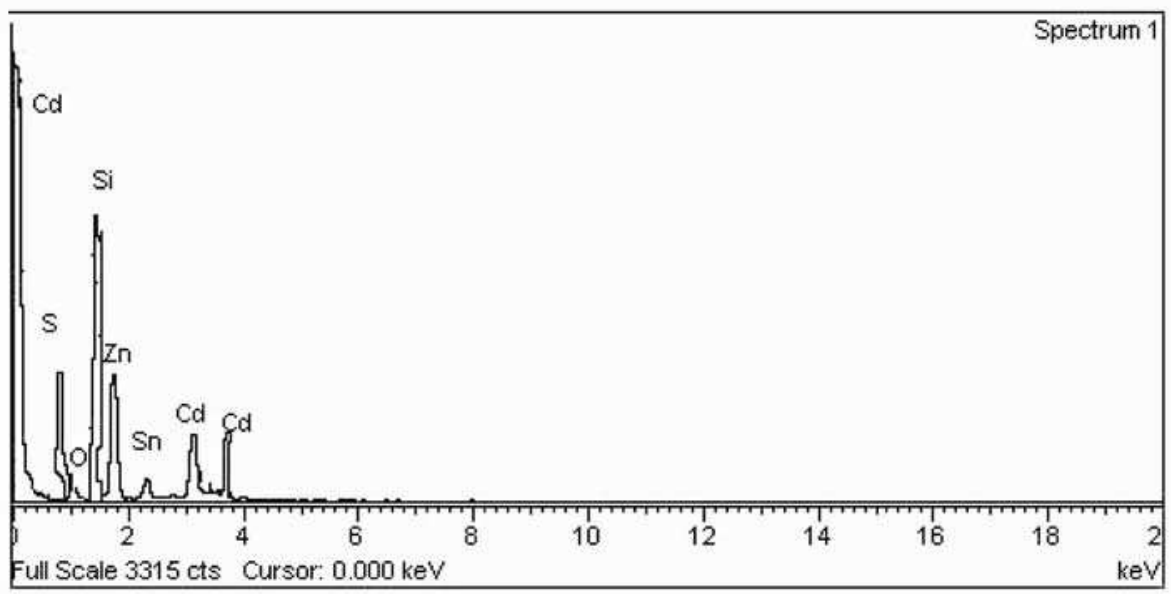

Figure 8. EDAX spectra for CdZnS : Sn film doped with 4 mol\% Sn.

due to the edge emission of CdZnS. Thomos and Hopfield $^{19,20}$ attributed the edge emission to transitions associated with donor/acceptor exciton complexes. Jeong and $\mathrm{Yu}^{20}$ observed the excitonic effects in $\mathrm{CdS}$ at RT. Thus, in the present case also the edge emission can be attributed to excitonic transitions. In the present study, a single broad peak is observed in CdZbS : Sn. Due to the similar excitonic nature of emission it can be attributed to 
Table 3. EDAX elemental analysis for undoped $\mathrm{CdZnS}$ and CdZnS : Sn for 2 and 4 mol\% Sn doping.

\begin{tabular}{|c|c|c|c|c|c|c|}
\hline \multirow[b]{2}{*}{ Elements } & \multicolumn{2}{|c|}{$\mathrm{CdZnS}$} & \multicolumn{2}{|c|}{ CdZnS : Sn 2 mol\% } & \multicolumn{2}{|c|}{$\mathrm{CdZnS}: \mathrm{Sn} 4 \mathrm{~mol} \%$} \\
\hline & Weight (\%) & Atomic (\%) & Weight (\%) & Atomic (\%) & Weight (\%) & Atomic (\%) \\
\hline $\mathrm{Cd}$ & 53.27 & 10.71 & 77.54 & 64.99 & 50.69 & 63.12 \\
\hline $\mathrm{Zn}$ & 5.43 & 5.34 & 6.62 & 2.22 & 6.97 & 6.04 \\
\hline S & 46.25 & 65.31 & 48.84 & 23.32 & 37.77 & 6.69 \\
\hline $\mathrm{Si}$ & 17.13 & 13.77 & 11.36 & 6.62 & 26.37 & 18.71 \\
\hline $\mathrm{O}$ & 4.89 & 3.44 & 6.65 & 0.87 & 3.56 & 1.77 \\
\hline $\mathrm{Sn}$ & - & - & 2.63 & 1.45 & 3.90 & 2.42 \\
\hline $\mathrm{Ca}$ & 2.52 & 1.42 & 1.27 & 0.53 & 1.52 & 1.25 \\
\hline
\end{tabular}

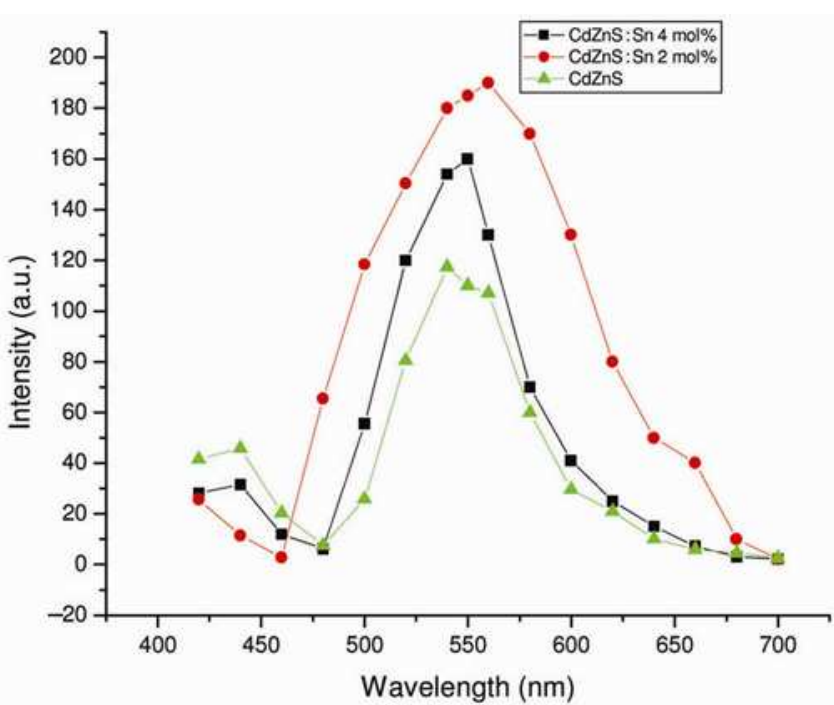

Figure 9. PL emission spectra of $\mathrm{CdZnS}$ and $\mathrm{CdZnS}:$ Sn with 2 and 4 mol\% Sn doping.

radioactive decay of free exciton. The PL emission in $\mathrm{CdZnS}: \mathrm{Sn}$ is significantly broader than pure $\mathrm{CdZnS}$ due to excitonic effects. ${ }^{2,19}$ Full-width at half-maxima (FWHM) of the CdZnS is reduced with the Sn doping into $\mathrm{CdZnS}$, the reduction in the FWHM of the green emission peak is possibly due to the formation of new recombination centres with Sn doping. Compared with the undoped $\mathrm{CdZnS}$, the PL spectra of the doped $\mathrm{CdZnS}$ nanostructures show a red shift in the emission spectra. This shift may be attributed to the shrinkage of bandgap and also the increasing carrier concentration with Sn doping.

\subsection{UV absorption spectra}

The absorption spectra of undoped $\mathrm{CdZnS}$ and Sn-doped CdZnS films were measured in the range of 200-800 nm; based on the absorption spectra the optical bandgap $E_{\mathrm{g}}$ was obtained by extrapolating the linear portion of the plot $(\alpha h v)^{2} v s$. $h v$ to $\alpha=0$ according to the following equation

$$
\alpha=A\left(h v-E_{\mathrm{g}}\right)^{n},
$$

where $h v$ is the photon energy, $E_{\mathrm{g}}$ the optical bandgap, $A$ the edge parameter and $n=1 / 2$ for direct gap material.

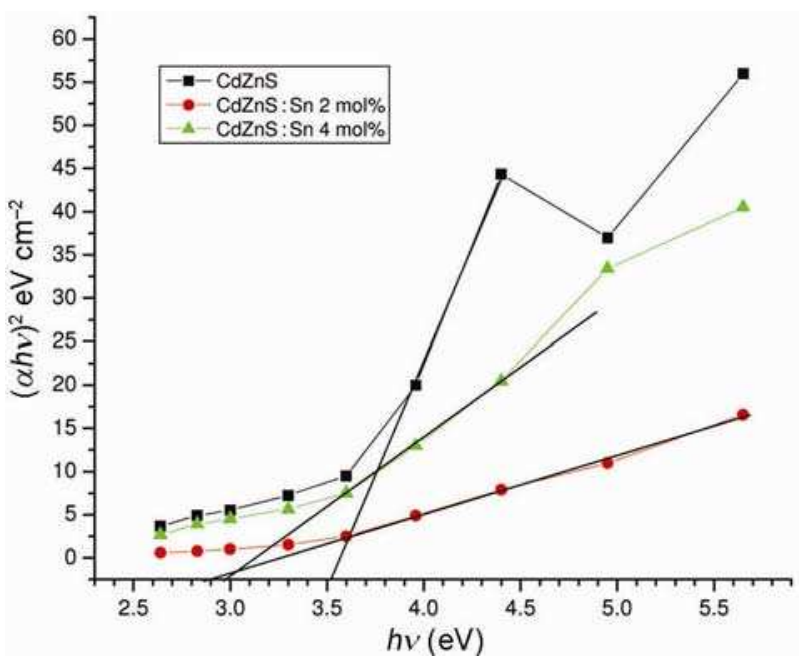

Figure 10. Tauc's plot for $\mathrm{CdZnS}$ and $\mathrm{CdZnS}: \mathrm{Sn}$ film with 2 and $4 \mathrm{~mol} \%$ Sn doping.

The optical bandgap $E_{\mathrm{g}}$ of undoped $\mathrm{CdZnS}$ and Sn-doped $\mathrm{CdZnS}$ films is shown in figure 10. UV-absorption spectra of the CdZnS nanoparticles for pure 2 and $4 \mathrm{~mol} \% \mathrm{Sn}$ doping are shown in figure. Based on these absorption spectra the absorption edge for each compound was determined. Optical studies show that the bandgap decreases significantly for pure $\mathrm{CdZnS}$ to Sn-doped $\mathrm{CdZnS} .^{21,22}$ Band-to-band absorption is seen at $3.5 \pm$ $0.05,3 \pm 0.05$ and $2.9 \pm 0.05 \mathrm{eV}$, respectively, for pure $\mathrm{CdZnS}$ and $\mathrm{CdZnS}$ : Sn for 2, 4 mol\% Sn-doped nanoparticles. Increase in $\mathrm{Sn}$ doping concentration decreases the optical bandgap of CdZnS films. This shift in the optical bandgap may be attributed to the band shrinkage effect because of increasing carrier concentration. ${ }^{23}$ Decrease in the bandgap for Sn doping can also be explained on the basis of the model of density of states in amorphous solids proposed by Mott and Davis. ${ }^{24}$ The small shift in the absorption peaks is attributed to the doping of $\mathrm{Sn}$ into $\mathrm{CdZnS}$. With doping of Sn absorption edge slightly shifts towards the longer wavelength region, which may be attributed to the increase in the grain size.

\section{Conclusions}

$\mathrm{CdZnS}$ : Sn nanoparticles with different Sn concentrations have been synthesized by the chemical bath deposition 
method. XRD pattern reveals the formation of cubic and hexagonal structures of $\mathrm{CdZnS}: \mathrm{Sn}$ (2 and 4 mol\%) with peak shift towards lower angle, which confirms the incorporation of Sn. XRD studies show that crystallite size increases with the increase in the concentration of $\mathrm{Sn}$. EDAX spectra support the presence of major chemical element. SEM study shows that grain size increases with the increase in the concentration of Sn. AFM study indicates that roughness of film surface decreases, whereas average radial value increases with the increase in the concentration of $\mathrm{Sn}$. Compared to pure $\mathrm{CdZnS}$, the decrease in the band-gap energy value of $\mathrm{CdZnS}: \mathrm{Sn}$ nanoparticles illustrates quantum confinement effect. For Sn-doped CdZnS, the emission intensity was found to be a maximum with slight shift towards the higher wavelength compared to bulk $\mathrm{CdZnS}$. Intense PL emission was observed for the incorporation of $\mathrm{Sn}$ ions into $\mathrm{CdZnS}$ nanoparticles, which will be useful for high-efficient EL devices and also possible for making full colour device applications.

\section{Acknowledgements}

We thank Dr V Ganesan, Dr Mukul Gupta, Dr N P Lalla and Dr Phase UGC-DAE-CSR, Indore, for providing XRD, AFM, TEM and SEM with EDAX facilities. We are also thankful to $\mathrm{Mr}$ Mohan Kumar Gangrade, $\mathrm{Mr}$ Layanta Behra and Ms Preeti Bhardwaj for conducting the measurements.

\section{References}

1. Maqbool M, Ahmad I, Richardson H H and Kordesch M E 2007 Appl. Phys. Lett. 91193511

2. Karpier I A 2014 Int. J. Miner. Metall. Mater. 21832
3. Maqbool M, Richardson H H and Kordesch M E 2007 J. Mater. Sci. 425657

4. Maqbool M 2006 Eur. Phys. J. Appl. Phys. 3431

5. Okamoto K, Yoshimi T and Miura S 1988 Appl. Phys. Lett. 53678

6. Jayaraj M K and Vallabhan C P G 1991 J. Electrochem. Soc. 1381512

7. Lozykowski H J, Jadwisienkzak W M and Brown I 2000 J. Appl. Phys. $\mathbf{8 8} 210$

8. Liu G K, Zhuang H Z and Chen X Y 2002 Nano Lett. 2535

9. Zych E, Hreniak D and Strek W 2002 J. Phys. Chem. B 106 3805

10. Liqiang J, Xiaojun S, Baifu X, Baiqi W, Weimin $\mathrm{C}$ and Honggang F 2004 Mater. Sci. Technol. 12148

11. Guo G, Li D, Wang Z and Guo H 2005 J. Rare Earths 23 362

12. Vij A, Singh S, Kumar R, Lochab S P, Kumar V V S and Singh N 2009 J. Phys. D: Appl. Phys. 42105103

13. Sharma G, Chawla P, Lochab S P and Singh N 2009 Radiat. Effects Defects Solids 164763

14. Kumar V, Pitale S S, Mishra V, Nagpure I M, Biggs M M and Ntwaeaborwa O M 2010 J. Alloys Compd. 492 L8-5

15. Petre D, Pintilie I, Pentia E, Pintilie I and Botila T 1999 Mater. Sci. Eng. B $\mathbf{5 8} 238$

16. Khallaf H, Chai G, Lupan O, Chow L, Park S and Schulte A 2009 Appl. Surf. Sci. 2554129

17. Davila-Pintle J A, Lozada-Morales R L, Palomino-Merino M R, Rivera-Márquez J A, Portillo-Moreno $\mathrm{O} \mathrm{P}$ and Zelaya-Angel O Z 2007 J. Appl. Phys. 101013712

18. Devi R, Kalita P K, Purkayastha P and Sharma B K 2008 Indian J. Phys. 82707

19. Thomas D G and Hopfield J 1962 J. Phys. Rev. 1282135

20. Jeong T S and Yu P Y 2000 J. Phys. Soc. (Korea) 36102

21. Roy P and Srivastava S K 2009 J. Phys. D 394771

22. Saravanan L 2012 Mater. Lett. 66343

23. Benelmadjat H, Boudine B, Halimi O and Sebais M 2009 Opt. Laser Technol. 41630

24. Mott N and Davis E 1979 Electronic processes in noncrystralline materials (Oxford, UK: Clarendon) 2nd edn, vol. $17, \mathrm{p} 122$ 